\title{
Modulation of hypovitaminosis D-induced islet dysfunction and insulin resistance through direct suppression of the pancreatic islet renin-angiotensin system in mice
}

\author{
Q. Cheng • B. J. Boucher • P. S. Leung
}

Received: 9 August 2012 / Accepted: 26 November 2012 /Published online: 19 December 2012

(C) Springer-Verlag Berlin Heidelberg 2012

\begin{abstract}
Aims/hypothesis Vitamin D is necessary for normal insulin action and suppresses renin production. Increased renin-angiotensin system (RAS) activity causes islet damage, including reduced insulin secretion. We therefore sought to determine whether hypovitaminosis D-induced upregulation of islet RAS in vivo impairs islet cell function and increases insulin resistance, and whether pharmacological suppression of the RAS during continuing vitamin $\mathrm{D}$ deficiency might correct this. Methods C57BL/6 mice were rendered vitamin D-deficient by diet, and glucose and insulin tolerance was assessed. The expression and translation of islet functional, and islet RAS, genes were measured and the effects of pharmacological renin suppression examined.

Results Mice with diet-induced hypovitaminosis D developed impaired glucose tolerance, increased RAS component expression and impaired islet function gene transcription. Treatment with pharmacological renin inhibition (aliskiren), without vitamin D status correction, reduced islet RAS overreactivity, islet dysfunction and insulin resistance, and improved glucose tolerance.

Conclusions/interpretation Upregulation of islet RAS genes can contribute to hypovitaminosis D-induced impairment of islet function and increase insulin resistance independently
\end{abstract}

Electronic supplementary material The online version of this article (doi:10.1007/s00125-012-2801-0) contains peer-reviewed but unedited supplementary material, which is available to authorised users.

Q. Cheng · P. S. Leung $(\bowtie)$

School of Biomedical Sciences, Faculty of Medicine, The Chinese University of Hong Kong, Room 609A, Lo Kwee-Seong

Integrated Biomedical Sciences Building,

Shatin, Hong Kong Special Administrative Region,

People's Republic of China

e-mail: psleung@cuhk.edu.hk

B. J. Boucher

Centre for Diabetes, Bart's and The London School of Medicine and Dentistry, Queen Mary University of London, London, UK of vitamin D status. Thus, our findings support the use of RAS inhibitors in impaired glucose homeostasis or early diabetes. They also suggest that combining RAS inhibition with correction of hypovitaminosis D might be useful in treating impaired glycaemic control and also in type 2 diabetes prevention. However, the use of aliskiren in established diabetes is contraindicated due to the increased risk of side effects such as hyperkalaemia, so other more suitable RAS blockers need to be identified.

Keywords Glucose homeostasis · Insulin resistance · Pancreatic islets $\cdot$ Renin-angiotensin system $\cdot$ Renin inhibitor . Type 2 diabetes · Vitamin D

$\begin{array}{ll}\text { Abbreviations } & \\ \mathrm{AT}_{1} & \text { Angiotensin II type 1 } \\ \text { FOXO1 } & \text { Forkhead box O1 } \\ \text { GSIS } & \text { Glucose-stimulated insulin secretion } \\ \text { HOMA-B } & \text { HOMA of beta cell function } \\ \text { HOMA-IR } & \text { HOMA of insulin resistance } \\ \text { IPGTT } & \text { Intraperitoneal glucose tolerance test } \\ \text { ITT } & \text { Insulin tolerance test } \\ \text { KO } & \text { Knockout } \\ 1,25(\mathrm{OH})_{2} \mathrm{D}_{3} & \text { Calcitriol } \\ 25(\mathrm{OH}) \mathrm{D}_{3} & \text { 25-Hydroxyvitamin D } \\ \text { PDK1 } & \text { Phosphoinositide-dependent kinase 1 } \\ \text { PTH } & \text { Parathyroid hormone } \\ \text { RAS } & \text { Renin-angiotensin system }\end{array}$

\section{Introduction}

Accumulating evidence has demonstrated many functions of vitamin D beyond its classical roles in calcium homeostasis and bone health. Experimental and clinical studies have implicated poor vitamin D repletion as a risk factor for numerous diseases, including metabolic syndrome [1]. Low serum 
25-hydroxyvitamin $\mathrm{D}\left(25[\mathrm{OH}] \mathrm{D}_{3}\right)$ concentrations lead to defective insulin secretion, reduced glucose homeostasis, and increased risk of metabolic syndrome and type 2 diabetes, both experimentally and in cross-sectional studies in humans $[2,3]$. These risks reflect increases in insulin resistance as well as islet beta cell dysfunction [4]. Higher baseline vitamin D status can predict better islet function, better glucose tolerance and reduced risk of hyperglycaemia prospectively [5]. However, observations from clinical studies remain inconclusive with regard to the causality of associations between vitamin $\mathrm{D}$ status and diabetes risk, as both conditions are associated with factors such as obesity and sodium intake, and there is also variation between studies [6]. Vitamin D supplementation can reduce insulin resistance in human deficiency [1], but it is not clear whether it can reduce insulin resistance or improve islet function in established diabetes; thus, further investigation of the underlying mechanisms is warranted.

$V D R$ polymorphisms are common and contribute to the modulation of serum $25(\mathrm{OH}) \mathrm{D}_{3}$ concentrations and to the determination of some relevant aspects of vitamin D function affecting the renin-angiotensin system (RAS) in humans [7]; moreover, in some human studies, polymorphism, gene expression and formation of the VDR were associated with variation in insulin secretion [8]. Vitamin $\mathrm{D}$ status is also associated directly with insulin secretion in murine islets [9], and mice with mutant $V d r$ have impaired insulin gene expression and secretion [10]. However, it remains uncertain whether there are mechanisms by which vitamin $\mathrm{D}$ affects islet function and insulin sensitivity, other than through direct effects on calcium metabolism [11].

Many clinical studies suggest that treatment with RAS blockade is associated with a reduced type 2 diabetes risk and fewer diabetic complications [12]. Our previous work has demonstrated: (1) the existence of a local pancreatic islet RAS [13]; (2) that islet function is improved in mouse models of diabetes by angiotensin II type $1\left(\mathrm{AT}_{1}\right)$ receptors antagonism [14, 15]; and (3) that local islet RAS can regulate islet cell proliferation and apoptosis, while modulating oxidative stress and beta cell mass $[14,16]$. Moreover, clinical and basic studies implicate additional factors regulated by or affecting, directly or indirectly, the islet RAS [14, 17]. Overall, suppression of islet RAS presents a potential target for the reduction of type 2 diabetes risk and, potentially, for the protection of islet function in type 2 diabetes.

The RAS is recognised to be a major blood pressure regulation system, and associations between hypertension and vitamin D deficiency have been suggested by several clinical studies [18]. The rate-limiting RAS component, renin, was shown to be suppressed by vitamin D in a study on $V d r$ knockout $(\mathrm{KO})$ mice, which develop elevated renin expression [19]. Mice without the vitamin D-activating $1 \alpha$-hydroxylase develop hyperreninaemia, independently of calcium levels [20]. The administration of calcitriol $\left(1,25[\mathrm{OH}]_{2} \mathrm{D}_{3}\right)$, the active hormonal metabolite of vitamin $\mathrm{D}$, or its analogues, reduces plasma renin activity and angiotensin II levels in experiments and in humans [21, 22]. Vitamin D status has shown inverse relationships with plasma renin activity in humans [23, 24], while activated vitamin $\mathrm{D}$ and $\mathrm{AT}_{1}$ receptor antagonism have synergistic beneficial effects on RAS regulation and on outcomes in diabetic nephropathy [25].

Since pancreatic islet RAS components are involved in the regulation of whole-body glycaemic control, vitamin D availability can be expected to contribute to modulation of this process. Recently, we found that in isolated islets 1,25 $(\mathrm{OH})_{2} \mathrm{D}_{3}$ provided potential protection against and ameliorated RAS component overabundance induced by hyperglycaemic conditions, as well as increasing insulin synthesis and secretion as expected [26]. However, it remains to be determined whether islet RAS mediates the effects of vitamin D deficiency on glycaemic control in vivo.

The present study is therefore based on the hypothesis that vitamin D deficiency may lead to increased islet RAS activity in vivo, contributing to abnormal glucose homeostasis. To test this hypothesis, we examined glucose tolerance, insulin sensitivity, islet architecture and RAS component activity, islet insulin secretion and related gene activity in genetically normal mice with diet-induced vitamin D deficiency, with and without pharmaceutical RAS inhibition. Our aim was to determine whether RAS blockade can reduce hypovitaminosis D-induced disorders of glucose homeostasis in animals with untreated vitamin D deficiency.

\section{Methods}

Animals Vitamin D deficiency was induced by feeding 4-week-old male C57BL/6 mice with a vitamin Ddeficient diet (TD89123; Harlan Teklad, Madison, WI, USA) for 8 weeks and control groups with a normal, vitamin D-containing diet (TD89124; Harlan Teklad). Mice were housed under ultraviolet B-free incandescent light to minimise endogenous vitamin D production. Blood glucose and body weight were recorded regularly. Mice were killed for further study when aged 12 weeks. The animal studies were approved by the Laboratory Animal Services Center of the Chinese University of Hong Kong (Ref No. 08/049/ERG).

Measurement of serum 25(OH) $D_{3}$ and $1,25(\mathrm{OH})_{2} \mathrm{D}_{3}$ concentrations Retro-orbital blood samples were collected from mice, centrifuged at $1,000 \mathrm{~g}$ for $10 \mathrm{~min}$ and serum aliquots stored at $-80^{\circ} \mathrm{C}$ until assay for $25(\mathrm{OH}) \mathrm{D}_{3}$ and $1,25(\mathrm{OH})_{2} \mathrm{D}_{3}$ using IDS-EIA kits (Immunodiagnostics-Systems, Boldon, UK) according to the manufacturer's protocol $(\mathrm{CV}<10 \%)$.

Treatment with a renin inhibitor Aliskiren (CGP060536) was provided by Novartis Pharma, Basel, Switzerland. After 
8 weeks of vitamin D-deficient diet treatment, 12 -week-old mice that had been fasted for $6 \mathrm{~h}$ and had fasting blood glucose $>9 \mathrm{mmol} / \mathrm{l}$ were treated for 7 days with aliskiren $\left(30 \mathrm{mgkg}^{-1} \mathrm{day}^{-1}\right)$ by daily gavage. Pancreatic islets were then isolated for further study.

Isolation of pancreatic islets Pancreatic islets were isolated as described previously in our laboratory [26]. Briefly, pancreatic islets were isolated from the pancreases from the different groups of mice by intra-ductal injection with $0.3 \mathrm{mg} / \mathrm{ml}$ collagenase-P (Roche Diagnostics, Mannheim, Germany) in Hanks'-balanced-salt-solution (Sigma-Aldrich, St Louis, MO, USA). After washing and gradient centrifugation $(500 \mathrm{~g})$, isolated islets were hand-picked under a stereomicroscope.

Pancreatic islet staining Immunohistochemistry was used for morphological assessments, and to locate pancreatic islet proteins and gene expression [14, 26]. Briefly, air-dried cryo-sections were rinsed with PBS, followed by $1 \mathrm{~h}$ of blocking using $6 \%(\mathrm{wt} / \mathrm{vol}$.) normal donkey serum (Jackson-ImmunoResearch, West-Grove, PA, USA). Primary antibodies against insulin (Invitrogen Life Technologies, Carlsbad, CA, USA) and/or glucagon (Abcam, Cambridge, MA, USA) and/or Ki67 (Abcam) were added and incubated on the slides overnight at $4{ }^{\circ} \mathrm{C}$. After three washes with PBS, appropriate fluorescent-conjugated secondary antibodies were added to the slides, which were then incubated at room temperature for $1 \mathrm{~h}$. After counterstaining with DAPI, slides were washed three times with PBS and mounted using a medium (VectaShield; Vector-Laboratories, Burlingame, CA, USA). Signals were then detected by fluorescent microscopy (DMLB digital camera; Leica, Heidelberg, Germany).

Haematoxylin-eosin staining was used to examine islet morphology and size. Briefly, freshly cut, air-dried pancreatic sections were rinsed with PBS and washed twice with double distilled $\mathrm{H}_{2} \mathrm{O}$ before haematoxylin staining for $1 \mathrm{~min}$ and rinsing in Scott's tap water for colour development. Slides were then counterstained with eosin. After washing with water and graded dehydration using ethanol and xylene, slides were mounted using entellan (Merck, Darmstadt, Germany). Islet size was then measured by automatic histomorphometry (ImageJ software; http://rsb.info.nih.gov/ij) [27].

Islet mRNA expression Total islet mRNA was extracted by TRIzol reagent (GIBCO/BRL-Invitrogen, Carlsbad, CA, USA) using the manufacture's protocol. Also using the manufacture's protocol (Invitrogen), first-strand cDNA was generated from $3 \mu \mathrm{g}$ mRNA in $20 \mu \mathrm{l}$ volume system using SuperScript II reverse transcriptase with oligo (dT) 12-18 primers. Real-time-PCR was used to quantify mRNA expression. A real-time PCR detection system (iCycler;
Bio-Rad Laboratories, Richmond, CA, USA) was used to perform real-time-PCR in amplification using $1 \mu$ undiluted cDNA as template, with SYBR-Green-I-mix (Bio-Rad). mRNA expression was detected and Gapdh mRNA coamplified as an internal control. Results were calculated using the $2^{-\Delta \Delta \mathrm{Ct}}$ method, while melting curve analysis was used to confirm PCR amplification specificity [26]. The primers used are listed in electronic supplementary material (ESM) Table. 1.

Western blot analysis Pancreatic islets isolated from mice in each of the different groups were used for western blotting. Total protein was extracted from 100 size-matched islets per group using CytoBuster Protein Extraction Reagent (Novagen, Darmstadt, Germany). After electrophoresis on $10 \%$ (wt/vol.) polyacrylamide gels, blotted protein was transferred to nitrocellulose membranes (Bio-Rad) and blocked for $1 \mathrm{~h}$ at room temperature with $5 \%$ (wt/vol.) skimmed milk in PBS with $0.1 \%$ (vol/vol.) Tween-20. Blotted membranes were then incubated overnight at $4{ }^{\circ} \mathrm{C}$ with primary antibodies against renin, renin receptor, $\mathrm{ACE}$ and $\mathrm{AT}_{1}$ receptor; appropriate horseradish peroxide-conjugated secondary antibodies were then added and incubated at room temperature for $1 \mathrm{~h}$. Labelled protein bands were revealed by western blotting detection reagents (ECL ${ }^{\text {plus}}$; GEHealthcare, Piscataway, NJ, USA) on autoradiography films (Fuji Film, Tokyo, Japan). Signals were measured using ImageJ software and expressed as fold change of the target protein:actin intensity ratios [26]. The antibodies used are listed in ESM Table 2.

Measurement of growth, glucose homeostasis and islet function Mouse body weight was recorded during growth and glucose homeostasis assessed as previously described [14]. In brief, for random blood glucose measurement mouse-tail vein blood was collected weekly between 10.00 and $11.00 \mathrm{~h}$ during growth. Fasting blood glucose and serum insulin concentrations were measured after $6 \mathrm{~h}$ of fasting. Glucose tolerance was assessed by an intraperitoneal glucose tolerance test (IPGTT). Briefly, after $6 \mathrm{~h}$ fasting, mice were given $1.5 \mathrm{~g} / \mathrm{kg}$ body weight of glucose by intraperitoneal injection. Blood glucose concentrations were measured in tail blood samples taken before and at 15, 30, 60, 90 and $120 \mathrm{~min}$ after glucose administration. Insulin sensitivity was assessed by an insulin tolerance test (ITT). After $4 \mathrm{~h}$ of fasting, mice were given an i.p. injection of insulin $(0.75 \mathrm{U} / \mathrm{kg}$ body weight), and blood glucose was measured in samples taken at $0,15,30$ and $60 \mathrm{~min}$ after insulin injection. To assess islet beta cell function, glucose-stimulated insulin secretion (GSIS) was examined as previously described [15]. Briefly, for each set of experiments, ten size-matched islets isolated from each different mouse group were incubated $\left(1 \mathrm{~h}, 37^{\circ} \mathrm{C}, 95: 5 \mathrm{O}_{2} / \mathrm{CO}_{2}\right)$ in KRB (supplemented with $10 \mathrm{mmol} / \mathrm{l}$ HEPES and $2 \mathrm{mg} / \mathrm{ml}$ 
BSA) with $1.7 \mathrm{mmol} / 1$ glucose, before transfer to KRB with $16.7 \mathrm{mmol} / \mathrm{l}$ glucose for a further hour in the same conditions. After incubation, the KRB supernatant fraction was collected for measurement of the insulin secreted using commercial mouse insulin ELISA kits (Mercodia, Uppsala, Sweden) $(\mathrm{CV}<10 \%)$. Data were expressed as the change of insulin released by each ten-islet group at $16.7 \mathrm{mmol} / \mathrm{l}$ glucose compared with $1.7 \mathrm{mmol} / 1$ glucose incubation $(\Delta$ insulin secretion). The HOMA of beta cell function (HOMA-B) was used to assess pancreatic beta cell function, calculated as described [28].

Measurements of serum calcium and parathyroid hormone levels Blood was collected from the heart immediately after death and random serum calcium levels measured by a calcium assay kit (Biovision, Mountain View, CA, USA). Serum parathyroid hormone $(\mathrm{PTH})$ concentrations were measured by mouse PTH(1-84) ELISA (Immunotopics, San Clemente, CA, USA) (CV $<10 \%)$.

Statistical analysis Results are expressed as mean \pm SEM for all groups of normally distributed data and as medians for non-normally distributed data. One-way ANOVA followed by Tukey's post-hoc test was used for multiple comparisons between groups. Two-tailed Student's $t$ tests or Mann-Whitney tests were used to compare parametric and non-parametric data respectively. A value of $p<0.05$ was considered statistically significant.

\section{Results}

$25(\mathrm{OH}) \mathrm{D}_{3}$ and $1,25(\mathrm{OH})_{2} \mathrm{D}_{3}$ concentrations in vitamin $D$-deficient diet-fed mice and the effects of this diet on growth The body weight of mice on vitamin D-deficient diets was similar to that of control-fed mice (Fig. 1a), while serum $25(\mathrm{OH}) \mathrm{D}_{3}$ and $1,25(\mathrm{OH})_{2} \mathrm{D}_{3}$ concentrations were greatly decreased after 8 weeks on the diet, confirming the establishment of vitamin D-deficiency (Fig. 1b, c).

Glucose homeostasis in vitamin D-deficient mice Mice fed the vitamin D-deficient diet exhibited higher blood glucose concentrations than control-fed mice from the age of 6 to 12 weeks (Fig. 2a, b). By 8 weeks (4 weeks after starting on the vitamin D-deficient diet), random blood glucose concentrations were already higher in vitamin D-deficient mice $(8.22 \pm 0.479 \mathrm{mmol} / 1$ [mean $\pm \mathrm{SEM}])$ than in normal-diet-fed controls $(6.675 \pm 0.5721 \mathrm{mmol} / \mathrm{l})$. At 12 weeks of age (8 weeks after starting on vitamin D-deficient diets), random blood glucose concentrations in vitamin $\mathrm{D}$-deficient mice were significantly higher than in control-fed mice (10.28 0.587 vs $7.925 \pm 0.701 \mathrm{mmol} / \mathrm{l}$ ) (Fig. 2a) and fasting glucose was also significantly increased $(9.673 \pm 0.425 \mathrm{mmol} / \mathrm{l})$ vs normal-diet-fed mice $(6.9 \pm 0.609 \mathrm{mmol} / \mathrm{l})$ (Fig. 2b). Glucose intolerance developed by 12 weeks of age in vitamin D-deficient mice (increased AUC vs normal-diet-fed mice) (Fig. 2c, d). Insulin tolerance was impaired in vitamin D-deficient mice, with abnormally high glucose concentrations at 15 and 30 min compared with those in control-fed mice after insulin injection (Fig. 2e). Serum insulin after $6 \mathrm{~h}$ fasting and the insulin resistance index (HOMA-IR) were also increased, the former significantly, in vitamin Ddeficient mice compared with controls (Fig. 2f, g). Islet function assessment showed that GSIS was blunted in vitamin D-deficient mouse islets (Fig. 2h), while the HOMA-B index, representing beta cell function, was decreased in islets from that mouse group (Fig. 2i).

Islet histomorphology in vitamin D-deficient mice The islet glucagon:insulin expression ratio in actively labelled areas of pancreas from vitamin D-deficient mice was similar to that in normal-diet-fed control mice (Fig. 3a). However, vitamin D-deficient mouse islets were larger (median 20,217.7 $\mu^{2}$ ) than normal-diet-fed control mouse islets

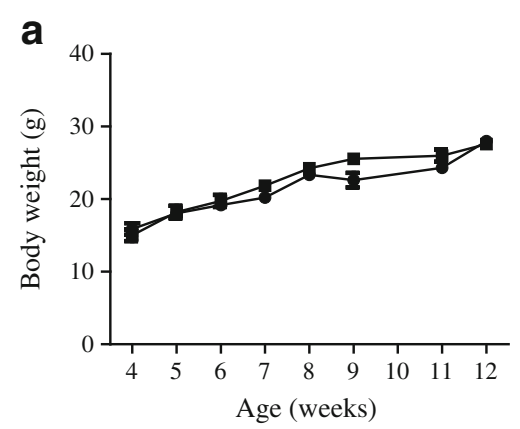

b

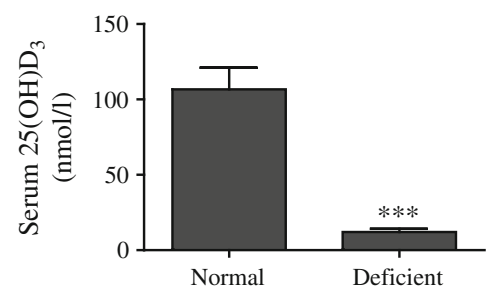

C

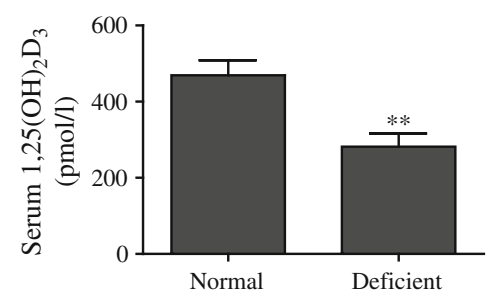

Fig. 1 Growth and vitamin D metabolite concentrations in vitamin D-deficient mice. (a) Body weight during growth from the age of 4 to 12 weeks in mice on the vitamin D-deficient diet (squares) and in those on a normal diet (circles). At the age of 12 weeks, after 8 weeks of vitamin D-deficient or normal diet, serum $25(\mathrm{OH}) \mathrm{D}_{3}$ (b) and 1,25 $(\mathrm{OH})_{2} \mathrm{D}_{3}$ (c) concentrations were measured by specific ELISA kits. $* * p<0.01$ and $* * * p<0.001$ vs normal diet 

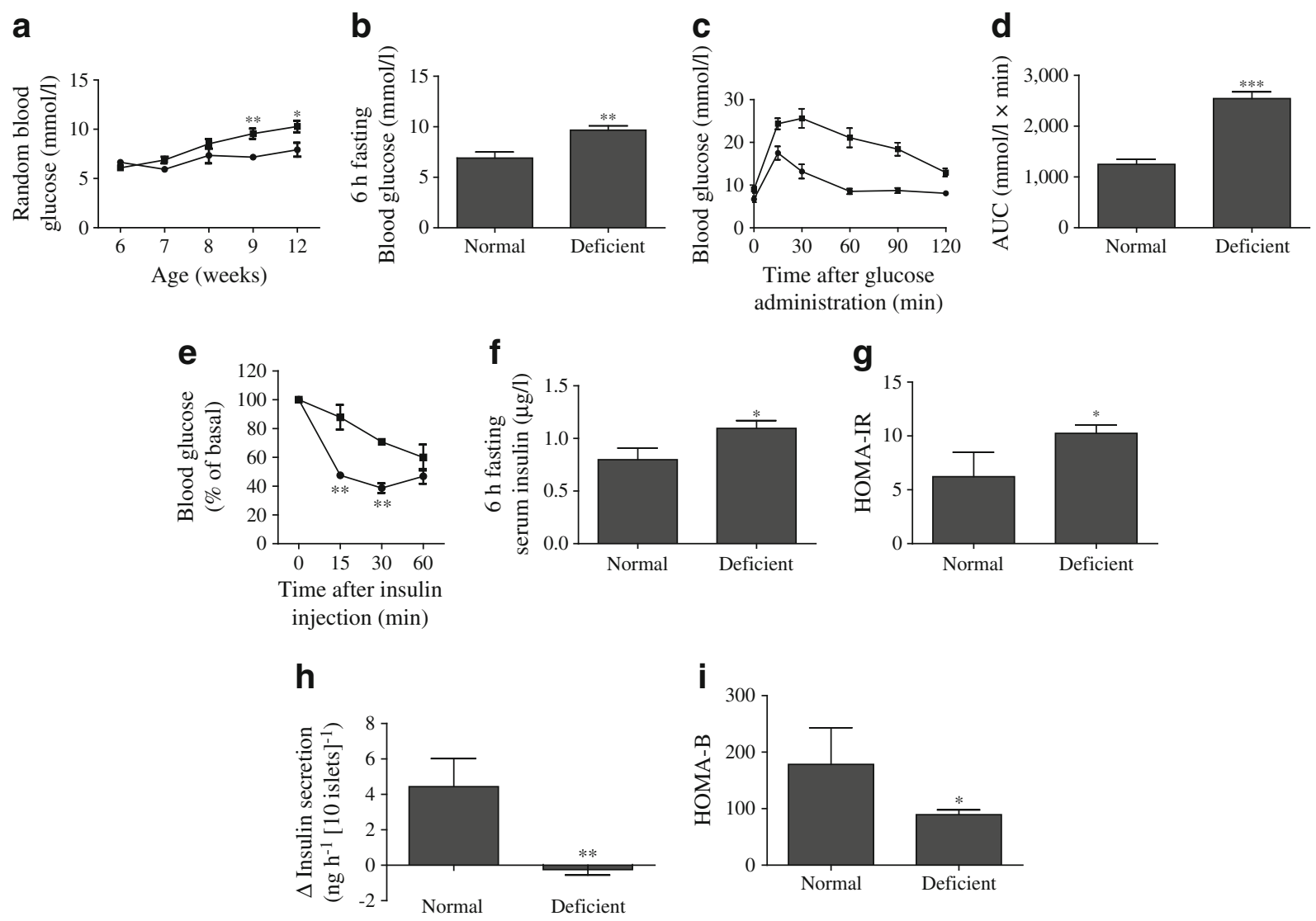

Fig. 2 Glucose homeostasis in vitamin D-deficient vs normal-diet-fed mice. (a) Random blood glucose concentrations during growth in mice treated with vitamin D-deficient (squares) or normal (circles) diet from 6 to 12 weeks of age. (b) Blood glucose after 6 h fast, (c) glucose tolerance by IPGTT and (d) glucose profiles calculated from IPGTT

(median $13,766.3 \mu \mathrm{m}^{2} ; p<0.0001$ by Mann-Whitney test) (Fig. 3b).

Regulation of islet RAS component levels in vitamin $D$-deficient mice The effects of hypovitaminosis D on islet RAS activity were examined through the profiles of several RAS components, including renin and the renin receptor. Protein levels of major islet RAS components, i.e. renin (Fig. 4a), renin receptor (Fig. 4b), ACE (Fig. 4c) and $\mathrm{AT}_{1}$ receptor (Fig. 4d), were all upregulated in islets from vitamin D-deficient vs those from islets of normal-dietfed mice.

Islet function-related gene expression in vitamin D-deficient mice Several genes related to islet function were significantly downregulated in vitamin D-deficient mouse islets, including Pdkl (Fig. 5a), Foxol (Fig. 5b), Tcf7l2 (Fig. 5c) and Glut2 (also known as Slc2a2) (Fig. 5d). Among islet insulinsignalling-related genes, Irs $1 \mathrm{mRNA}$ expression and the expression of the anti-oxidative stress-related gene catalase were downregulated in islets of vitamin D-deficient mice data as AUC in 12-week-old mice. (e) ITT, (f) $6 \mathrm{~h}$ fasting serum insulin concentration, (g) insulin sensitivity by HOMA-IR, (h) islet glucoseinduced insulin release during GSIS and (i) the HOMA-B index, all assessed in 12-week-old mouse/islet groups as above (a). ${ }^{*} p<0.05$, ${ }^{* *} p<0.01$ and $* * * p<0.001$ vs normal-diet-fed mice

(ESM Fig. 1a, b), although expression of the NADPH oxidase subunits $p 22$ (also known as $C y b a$ ) and $p 47$ (also known as Ncfl) was unchanged (ESM Fig. 1c, d). Consistent with the mRNA expression data, protein production of total IRS1, forkhead box O1 (FOXO1) and phosphoinositidedependent kinase 1 (PDK1) was decreased in vitamin D-deficient vs control mice islets (ESM Fig. 2a-c).

The effect of the renin inhibitor aliskiren on glucose homeostasis in vitamin D-deficient mice After 7 days of treatment with the renin inhibitor aliskiren, random and $6 \mathrm{~h}$ fasting blood glucose values in 12-week-old vitamin D-deficient mice were unchanged (Fig. 6a, b), while fasting serum insulin concentrations and HOMA-IR tended towards an increase (Fig. 6f, g). Impaired glucose tolerance in vitamin D-deficient mice was improved by aliskiren (Fig. 6c, d), as was insulin tolerance (assessed 15 min after insulin administration during an ITT) (Fig. 6e), i.e. postprandial, but not fasting insulin resistance was improved by RAS blockade. Islet beta cell function was significantly increased in aliskiren-treated vitamin D-deficient mice, as evidenced by 

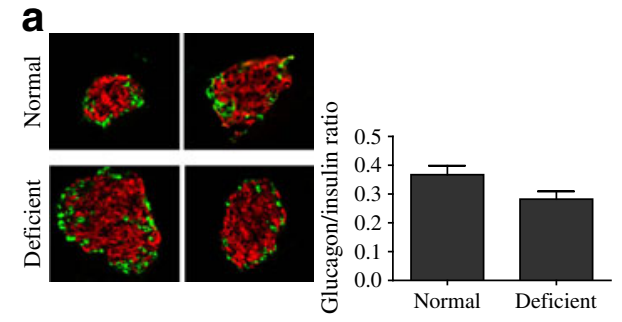

b
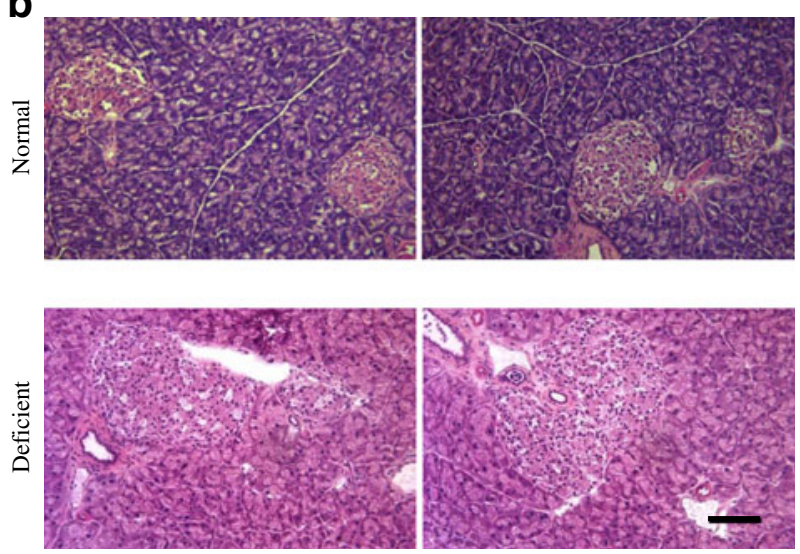

Fig. 3 Pancreatic islet histomorphology in 12-week-old normal-dietfed and vitamin D-deficient diet-fed mice. (a) Islets were immunostained with insulin (red) and glucagon (green) fluorescent-labelled specific antibodies and the glucagon:insulin ratio calculated automatically from data for areas that stained positive. Original magnification (a) $\times 200$. (b) Islets were stained with haematoxylin and eosin, and the measurement of islet cross-sectional areas was performed. Scale bar $100 \mu \mathrm{m}$

the increased GSIS (Fig. 6h) and HOMA-B index (Fig. 6i). However, serum $25(\mathrm{OH}) \mathrm{D}_{3}$ concentrations remained low in aliskiren-treated mice (Fig. 6j).

The effects of aliskiren on islet renin, renin receptor levels, islet function-related gene expression, islet cell proliferation, and on serum calcium and PTH levels in vitamin D-deficient mice In vitamin D-deficient mice, renin protein levels were not altered by aliskiren treatment (Fig. 7a), but renin receptor protein levels were reduced (Fig. 7b). Among genes relevant to islet function, no obvious changes were observed in Irs $1 \mathrm{mRNA}$ expression after aliskiren treatment (ESM Fig. 3a). Increases in Glut2 mRNA expression were marginal (Fig. 7c), while the decreased Pdk1 mRNA expression (Fig. 7d) seen in vitamin D-deficient mice was reversed after aliskiren treatment. Islet expression of the oxidative stressrelated genes, NADPH oxidase subunits $p 22$ and $p 47$, was unaltered by aliskiren treatment (ESM Fig. 3c, d). However, and significantly, the decrease in catalase mRNA expression seen in vitamin D-deficient animals was reversed by aliskiren (ESM Fig. 3b).

Islet size and morphology were unchanged by aliskiren treatment (data not shown), but the increase in islet alpha cell proliferation seen in vitamin D-deficiency (i.e. a
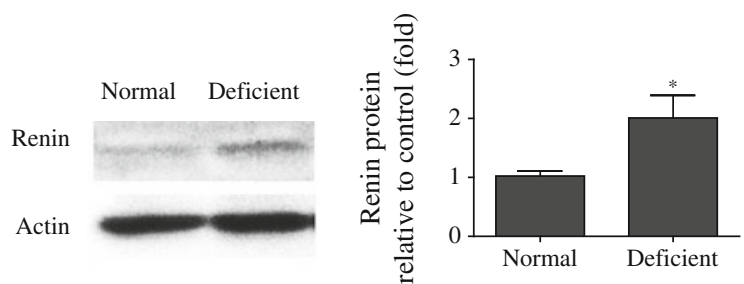

b

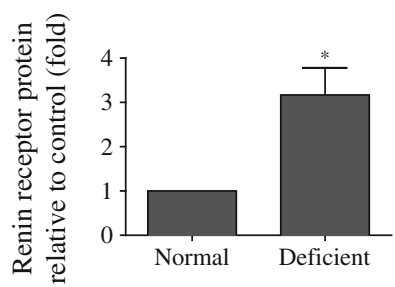

C
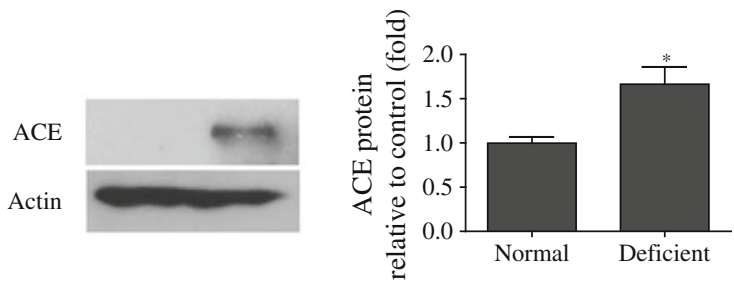

d

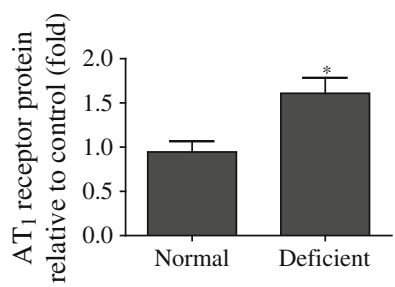

Fig. 4 Pancreatic islet RAS component levels in 12-week-old vitamin D-deficient vs normal-diet-fed mice. (a) Protein levels and statistical analysis of renin, (b) renin receptor, (c) $\mathrm{ACE}$ and (d) $\mathrm{AT}_{1}$ receptor in animals as labelled. ${ }^{*} p<0.05$ vs normal diet

increases in Ki67-labelled cells) was decreased by aliskiren treatment (ESM Fig. 4a, b), suggesting that renin a

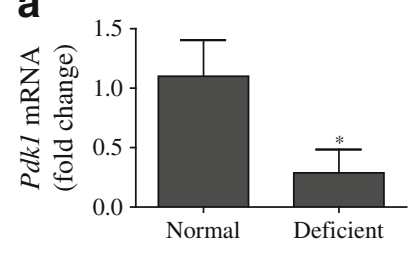

C

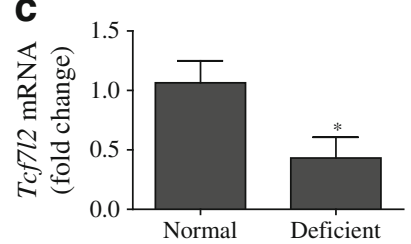

b

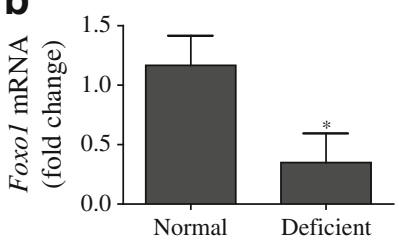

d

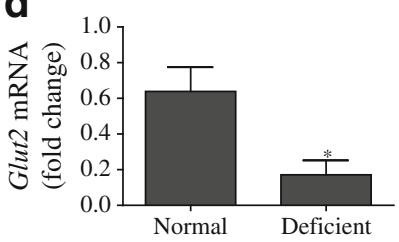

Fig. 5 Islet function-related gene expression in vitamin D-deficient mouse islets. (a) Transcription levels of Pdk1, (b) Foxo1, (c) Tcf7l2 and (d) Glut2 in islets from vitamin D-deficient diet-fed mice compared with normal-diet-fed mice. ${ }^{*} p<0.05$ vs normal diet 

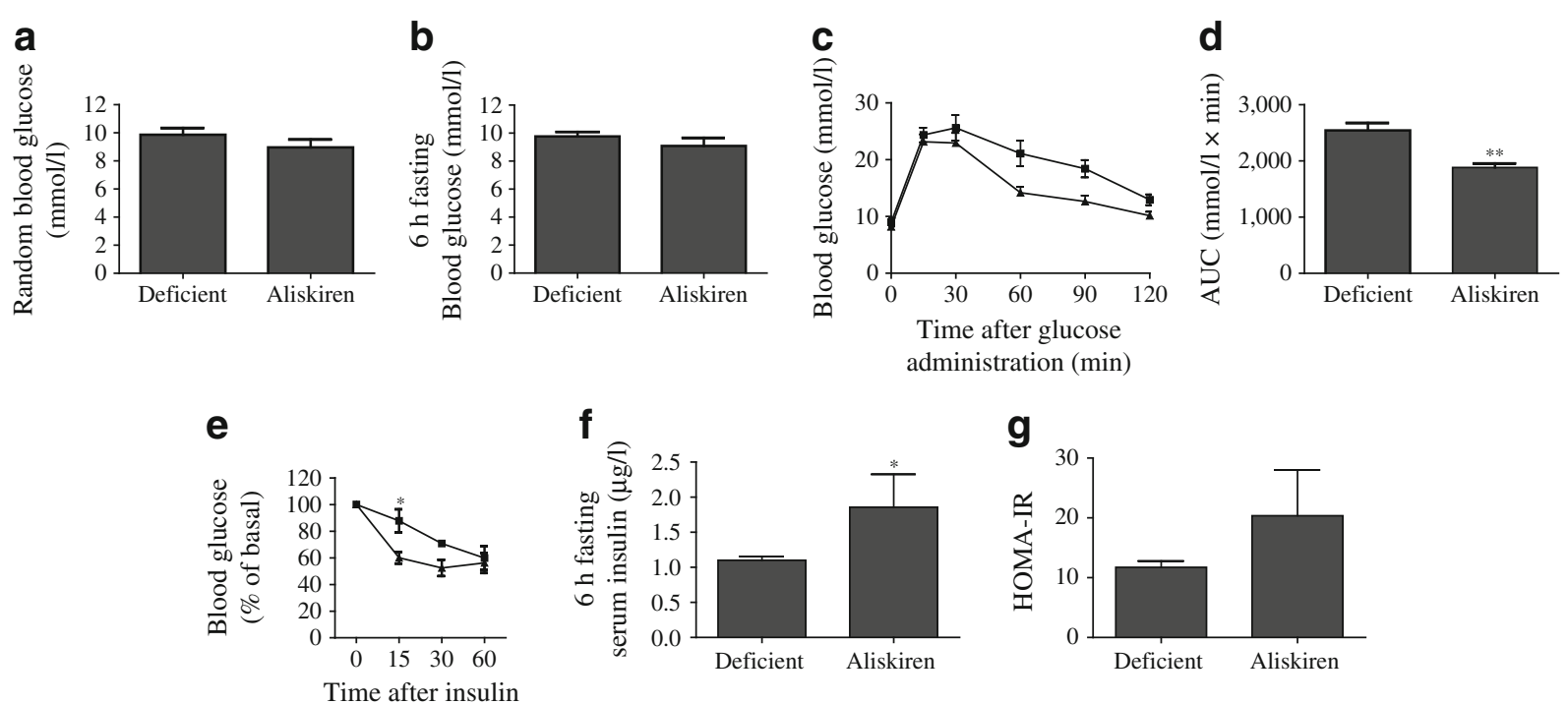

injection ( $\mathrm{min})$
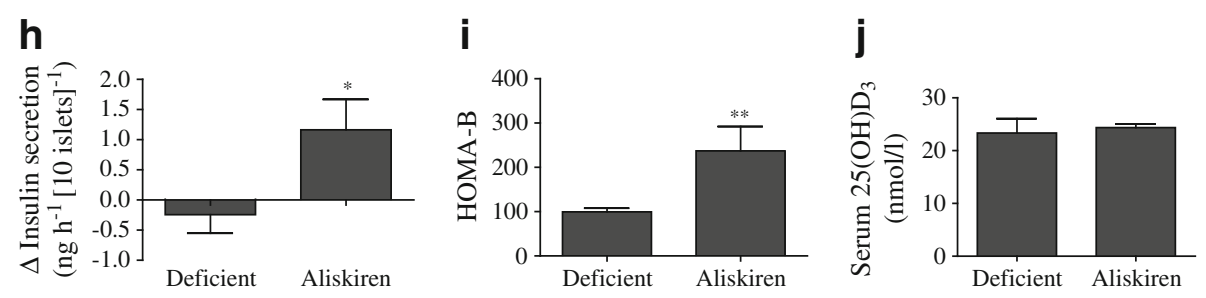

Fig. 6 The effect of aliskiren treatment on glucose homeostasis in vitamin D-deficient mice. (a) Random and (b) fasting (6 h) blood glucose in vitamin D-deficient mice and in vitamin D-deficient mice treated with aliskiren. (c) IPGTT and (d) the glucose profile calculated as AUC. (e) Blood glucose during an ITT at 0, 15, 30 and 60 min after insulin administration, and (f) fasting $(6 \mathrm{~h})$ serum insulin levels and (g)

inhibition exerts protective effects against increased glucagon action. We found no explanation for the increased islet size in vitamin D-deficient mice and this requires further study, as it may reflect increased cell proliferation or cell junction. Random calcium and PTH concentrations were similar in normal, vitamin D-deficient and vitamin D-deficient, aliskiren-treated groups of mice (ESM Fig. 4c, d).

\section{Discussion}

The present study confirms our earlier finding that chronic hypovitaminosis D increases local pancreatic islet RAS gene expression in vivo, and decreases islet beta cell function and insulin sensitivity, thereby contributing to loss of glycaemic control, with increased islet RAS component expression occurring independently of glycaemia (as also seen in $V d r$ KO mice) [26]. However, stunted growth and the short lifespan of $V d r$-KO mice limit their use in this research. Furthermore, in human studies, the associations between vitamin D status and insulin sensitivity are often lost in obesity the HOMA-IR index in animal groups as indicated. (h) Insulin release during GSIS in islets and (i) beta cell function by HOMA-B. (j) Mean serum $25(\mathrm{OH}) \mathrm{D}_{3}$ concentrations in vitamin $\mathrm{D}$-deficient mice, with or without aliskiren treatment. Squares, vitamin D-deficient diet; triangles, vitamin D-deficient diet + aliskiren. ${ }^{*} p<0.05$ and $* * p<0.01$ vs vitamin D-deficient diet only

[29], while vitamin D supplementation did not improve glucose homeostasis in non-deficient patients with type 2 diabetes [30]. We therefore extended these studies in vivo using a genetically normal mouse model, which was healthy apart from dietary vitamin D deficiency. This allowed us to demonstrate that the increased RAS activity induced by vitamin $\mathrm{D}$ deficiency can be ameliorated by renin blockade, with improvements in islet function, postprandial insulin sensitivity and glucose homeostasis, in vivo, despite continuing vitamin $\mathrm{D}$ deficiency. These findings support the proposal that RAS overactivity can contribute, mechanistically, to hyperglycaemia related to vitamin D deficiency and suggest that renin inhibition may protect islet function and reduce insulin resistance, thereby improving glycaemic control in vivo.

In addition to well-known effects on the circulatory system, clinical trials of RAS blockade/inhibition have demonstrated a reduction in risk of diabetes [31]. Key to the development of type 2 diabetes is the combination of insulin resistance and islet dysfunction; a reduction of these effects can reduce diabetes risk and glycaemia. Chronic RAS overactivation (systemic and local) is known to contribute to 
a

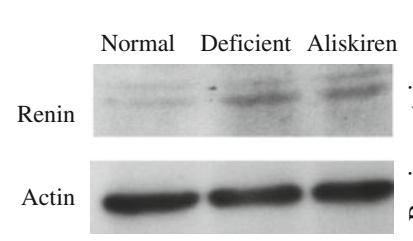

b

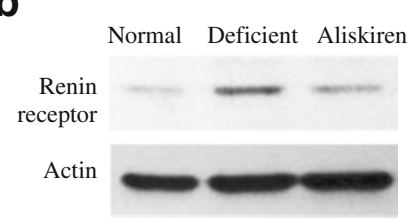

C
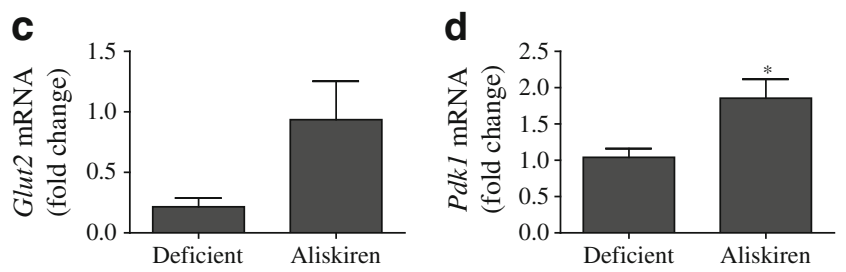

Fig. 7 The effects of aliskiren on islet RAS components and islet function-related gene expression in vitamin D-deficient mice. (a) Islet renin and (b) renin receptor protein content in mice on normal diet, vitamin D-deficient diet and vitamin-D deficient diet + aliskiren treatment. (c) Islet expression of Glut2 and (d) Pdk1 mRNA in vitamin D-deficient mice with or without aliskiren treatment. ${ }^{*} p<0.5$ and ${ }^{* *} p<0.01$ vs vitamin $\mathrm{D}$-deficient diet

insulin resistance, and RAS component blockade improves insulin sensitivity [32]. Angiotensin II regulates insulin actions in several peripheral tissues by modulating downstream signalling of the insulin receptor [33]. Inhibition of renin, the rate-limiting enzyme of the RAS, improves insulin sensitivity in adipocytes and skeletal muscles through effects on insulin action and glucose transport [34]. With the development of insulin resistance, reduced insulin secretion in response to glucose (GSIS) is a major hallmark of type 2 diabetes risk and it has been suggested that RAS blockade may prevent the beta cell loss that leads to overt diabetes. Isolated islets develop increased RAS component abundance in prolonged hyperglycaemia, with reduced GSIS and (pro)insulin synthesis [26, 35]. Indeed, our earlier studies showed that RAS blockade in pancreatic islets from diabetic animals improved islet function and glucose homeostasis, increased islet proliferation, reduced oxidative stress and inflammation in islets, and also reduced beta cell apoptosis $[14,15]$, thereby helping to prevent beta cell loss.

Elevated renin levels have been found in mutant $V d r$-KO mice [19]. Furthermore, inverse relationships between vitamin D status and RAS activity help explain the beneficial effects of optimal vitamin D replacement therapy in chronic renal failure and cardiovascular disorders [36, 37]. Since vitamin D suppresses renin and RAS activity, but RAS activity increases with hyperglycaemia (aggravating islet damage and insulin resistance), vitamin D deficiency may aggravate loss of glycaemic control through increased RAS activity. Thus, the reduction of RAS overactivity, whether by vitamin $\mathrm{D}$ replacement (as we recently showed in isolated islets) [26] or by pharmacological means, could improve islet function and insulin sensitivity.

Although our young, genetically intact, but vitamin D-deficient, mouse model showed no changes in body weight, serum total PTH or calcium, the increased islet RAS component expression we found was consistent with the known upregulation of human RAS activity by the common problem of hypovitaminosis D (low circulating $25\left[\mathrm{OH}_{3} \mathrm{D}_{3}\right.$ ) [38]. Glycaemia increased over time in our mouse model, with decreased GSIS and HOMA-B index by 3 months of age, and with glucose intolerance, impaired insulin sensitivity and fasting hyperglycaemia, which we suggest is due to the combination of increased islet RAS activity and decreased vitamin D availability (since vitamin D reduces RAS overactivity and improves GSIS in hyperglycaemia) [26]. Although aliskireninduced renin inhibition improved glycaemia, insulin sensitivity and islet function despite continuing vitamin D deficiency, the improvement in GSIS was only partial (by $25 \%$ ), suggesting that the reduction of insulin resistance was an important contributor to the beneficial effects of renin inhibition on glycaemic control. Reductions in overall insulin resistance (as seen in the ITT) and in glucose tolerance (in OGTT) were marked, while fasting HOMA-IR increased, suggesting that RAS blockade reduces postprandial, but not fasting, insulin resistance. Increased serum insulin levels were observed, suggesting that the improved islet insulin secretory ability may also partially contribute to glycaemic control.

Overall, our findings support the proposition that control of RAS overactivity could help counteract the adverse effects of hyperglycaemia and hypovitaminosis $\mathrm{D}$, through partially reducing insulin resistance, as well as by protecting islet beta cells. Additional support for this postulate is provided by several other aspects of our study. Islet FOXO1 abundance decreases in vitamin D-deficient states and FOXO1 normally increases beta cell mass, reduces insulin signalling [39] and signals islet enlargement, as in other models of type 2 diabetes [40]. Vitamin D deficiency-related Tcf7l2 downregulation, as in the present study, may aggravate hyperglycaemia, as $T c f 7 l 2$ variants and expression are associated with diabetic renal disease [41] and reduced insulin secretion [42]. Islets are themselves insulin-sensitive, through signalling pathways, including IRS1 and IRS2 [43]. Our finding of decreased Irs I transcription in the presence of vitamin D deficiency could contribute to reduced insulin action on islets, in turn impairing islet growth and function through increased islet insulin resistance [44]. Adverse angiotensin II-induced effects on the vasculature have been reported $[45,46]$. These effects normally regulate the maintenance of islet function and beta cell 
mass, probably due to similar effects on smooth muscle in vessel walls acting through target genes like $P d k 1$. Indeed, we found that the reduced Pdkl expression seen in vitamin D deficiency was corrected by RAS blockade, implying RAS involvement in PDK1 regulation.

Insulin-signalling is impaired by glucagon [47]; thus the reversal of vitamin D deficiency-induced proliferation of glucagon-secreting alpha cells that we found with aliskiren treatment may reduce or prevent potential overactivation of glucagon actions in vitamin D-deficient states. Islet GLUT2, the major islet glucose transporter, is reduced in type 2 diabetes and by hyperglycaemia in the presence of increased insulin resistance [48], but aliskiren is unlikely to improve glucose homeostasis through this mechanism, as GLUT2 was not affected by RAS blockade.

In contrast to data from genetically modified mouse models of diabetes [16], our vitamin D-deficient mouse model showed no gene defects related to reactive oxygen species, but the reduced islet catalase activity seen in vitamin D-deficient islets may worsen islet oxidative stress in vitamin D deficiency. Since we found that renin blockade increased catalase expression, therapeutic RAS blockade may increase antioxidant protection in the islets.

Our findings are relevant to reported reductions in the risk of diabetes with RAS blockade [12]. However, aliskiren can increase the risk of hypotension and hyperkalaemia in clinical use. Indeed, the US Federal Drugs Authority recently advised that aliskiren should not be given to patients with renal dysfunction or diabetes, due to the risk of diabetic nephropathy $[49,50]$. Other RAS-modulating medication that proves to be safe in patients with diabetes may have similar protective effects and, if so, may help protect against diabetes progression, as well as reducing the risk of diabetes. Further investigations are also needed to determine the detailed relationships between hypovitaminosis $\mathrm{D}$ and insulin resistance, as well as the underlying mechanisms.

\section{Acknowledgements Aliskiren was from Novartis, Basel, Switzerland (MTA \#33405).}

Funding This work was supported by the General Research Fund from the Research Grants Council of Hong Kong (reference numbers: CUHK 470709 and CUHK 468912), awarded to P.S. Leung.

Duality of interest The authors declare that there is no duality of interest associated with this manuscript.

Contribution statement QC contributed to the conception and design of the study, the acquisition of data, data analysis and interpretation, drafting and final approval of the manuscript. BJB contributed to data analysis and interpretation, manuscript revision and final approval of the manuscript. PSL contributed to the conception and design of the study, provision of study material, data analysis and interpretation, manuscript writing and final approval of the manuscript.

\section{Reference}

1. Boucher BJ (2011) Vitamin D insufficiency and diabetes risks. Curr Drug Targets 12:61-87

2. Boucher BJ, Mannan N, Noonan K, Hales CN, Evans SJ (1995) Glucose intolerance and impairment of insulin secretion in relation to vitamin D deficiency in east London Asians. Diabetologia 38:1239-1245

3. Forouhi NG, Luan J, Cooper A, Boucher BJ, Wareham NJ (2008) Baseline serum 25-hydroxy vitamin $d$ is predictive of future glycemic status and insulin resistance: the Medical Research Council Ely Prospective Study 1990-2000. Diabetes 57:2619-2625

4. Chiu KC, Chu A, Go VL, Saad MF (2004) Hypovitaminosis D is associated with insulin resistance and beta cell dysfunction. Am J Clin Nutr 79:820-825

5. Kayaniyil S, Retnakaran R, Harris SB et al (2011) Prospective associations of vitamin $\mathrm{D}$ with beta-cell function and glycemia: the PROspective Metabolism and ISlet cell Evaluation (PROMISE) cohort study. Diabetes 60:2947-2953

6. Vaidya A, Williams JS (2012) The relationship between vitamin D and the renin-angiotensin system in the pathophysiology of hypertension, kidney disease, and diabetes. Metabolism 61:450-458

7. Vaidya A, Sun B, Forman JP et al (2011) The Fok1 vitamin D receptor gene polymorphism is associated with plasma renin activity in Caucasians. Clin Endocrinol (Oxf) 74:783-790

8. Ogunkolade BW, Boucher BJ, Prahl JM et al (2002) Vitamin D receptor (VDR) mRNA and VDR protein levels in relation to vitamin D status, insulin secretory capacity, and VDR genotype in Bangladeshi Asians. Diabetes 51:2294-2300

9. Norman AW, Frankel JB, Heldt AM, Grodsky GM (1980) Vitamin $\mathrm{D}$ deficiency inhibits pancreatic secretion of insulin. Science 209:823-825

10. Zeitz U, Weber K, Soegiarto DW, Wolf E, Balling R, Erben RG (2003) Impaired insulin secretory capacity in mice lacking a functional vitamin D receptor. FASEB J 17:509-511

11. Labriji-Mestaghanmi H, Billaudel B, Garnier PE, Malaisse WJ, Sutter BC (1988) Vitamin D and pancreatic islet function. I. Time course for changes in insulin secretion and content during vitamin D deprivation and repletion. J Endocrinol Invest 11:577-584

12. Abuissa H, Jones PG, Marso SP, O'Keefe JH Jr (2005) Angiotensin-converting enzyme inhibitors or angiotensin receptor blockers for prevention of type 2 diabetes: a meta-analysis of randomized clinical trials. J Am Coll Cardiol 46:821-826

13. Lau T, Carlsson PO, Leung PS (2004) Evidence for a local angiotensin-generating system and dose-dependent inhibition of glucose-stimulated insulin release by angiotensin II in isolated pancreatic islets. Diabetologia 47:240-248

14. Cheng Q, Law PK, de Gasparo M, Leung PS (2008) Combination of the dipeptidyl peptidase IV inhibitor LAF237 [(S)-1-[(3-hydroxy1 -adamantyl)ammo]acetyl-2-cyanopyrrolidine] with the angiotensin II type 1 receptor antagonist valsartan [N-(1-oxopentyl)-N-[[2'-(1Htetrazol-5-yl)-[1,1'-biphenyl]-4-yl]methyl]-L- valine] enhances pancreatic islet morphology and function in a mouse model of type 2 diabetes. J Pharmacol Exp Ther 327:683-691

15. Chu KY, Lau T, Carlsson PO, Leung PS (2006) Angiotensin II type 1 receptor blockade improves beta-cell function and glucose tolerance in a mouse model of type 2 diabetes. Diabetes 55:367-374

16. Chu KY, Leung PS (2007) Angiotensin II type 1 receptor antagonism mediates uncoupling protein 2-driven oxidative stress and ameliorates pancreatic islet beta-cell function in young type 2 diabetic mice. Antioxid Redox Signal 9:869-878

17. Gerstein H, Yusuf S, Holman R, Bosch J, Pogue J (2004) Rationale, design and recruitment characteristics of a large, simple international trial of diabetes prevention: the DREAM trial. Diabetologia 47:1519-1527 
18. Li YC, Qiao G, Uskokovic M, Xiang W, Zheng W, Kong J (2004) Vitamin D: a negative endocrine regulator of the renin-angiotensin system and blood pressure. J Steroid Biochem Mol Biol 8990:387-392

19. Li YC, Kong J, Wei M, Chen ZF, Liu SQ, Cao LP (2002) 1,25Dihydroxyvitamin $\mathrm{D}(3)$ is a negative endocrine regulator of the renin-angiotensin system. J Clin Invest 110:229-238

20. Zhou C, Lu F, Cao K, Xu D, Goltzman D, Miao D (2008) Calcium-independent and 1,25(OH)2D3-dependent regulation of the renin-angiotensin system in 1alpha-hydroxylase knockout mice. Kidney Int 74:170-179

21. Bodyak N, Ayus JC, Achinger S et al (2007) Activated vitamin $\mathrm{D}$ attenuates left ventricular abnormalities induced by dietary sodium in Dahl salt-sensitive animals. Proc Natl Acad Sci U S A 104:16810-16815

22. Kimura Y, Kawamura M, Owada M et al (1999) Effectiveness of 1,25-dihydroxyvitamin D supplementation on blood pressure reduction in a pseudohypoparathyroidism patient with high renin activity. Intern Med 38:31-35

23. Tomaschitz A, Pilz S, Ritz E et al (2010) Independent association between 1,25-dihydroxyvitamin D, 25-hydroxyvitamin D and the renin-angiotensin system: The Ludwigshafen Risk and Cardiovascular Health (LURIC) study. Clin Chim Acta 411:1354-1360

24. Vaidya A, Forman JP, Hopkins PN, Seely EW, Williams JS (2011) 25-Hydroxyvitamin D is associated with plasma renin activity and the pressor response to dietary sodium intake in Caucasians. J Renin Angiotensin Aldosterone Syst 12:311-319

25. Zhang Z, Zhang Y, Ning G, Deb DK, Kong J, Li YC (2008) Combination therapy with AT1 blocker and vitamin D analog markedly ameliorates diabetic nephropathy: blockade of compensatory renin increase. Proc Natl Acad Sci U S A 105:15896-15901

26. Cheng Q, Li YC, Boucher BJ, Leung PS (2011) A novel role for vitamin D: modulation of expression and function of the local renin-angiotensin system in mouse pancreatic islets. Diabetologia 54:2077-2081

27. Morioka T, Asilmaz E, Hu J et al (2007) Disruption of leptin receptor expression in the pancreas directly affects beta cell growth and function in mice. J Clin Invest 117:2860-2868

28. Souza-Mello V, Gregorio BM, Cardoso-de-Lemos FS, de Carvalho L, Aguila MB, Mandarim-de-Lacerda CA (2010) Comparative effects of telmisartan, sitagliptin and metformin alone or in combination on obesity, insulin resistance, and liver and pancreas remodelling in C57BL/6 mice fed on a very high-fat diet. Clin Sci (Lond) 119:239-250

29. Muscogiuri G, Sorice GP, Prioletta A et al (2010) 25-Hydroxyvitamin D concentration correlates with insulin-sensitivity and BMI in obesity. Obes (Silver Spring) 18:1906-1910

30. Jorde R, Figenschau Y (2009) Supplementation with cholecalciferol does not improve glycaemic control in diabetic subjects with normal serum 25-hydroxyvitamin D levels. Eur J Nutr 48:349-354

31. Bosch J, Yusuf S, Gerstein HC et al (2006) Effect of ramipril on the incidence of diabetes. N Engl J Med 355:1551-1562

32. Kalupahana NS, Moustaid-Moussa N (2012) The renin-angiotensin system: a link between obesity, inflammation and insulin resistance. Obes Rev 13:136-149
33. Ogihara T, Asano T, Ando K et al (2002) Angiotensin II-induced insulin resistance is associated with enhanced insulin signaling. Hypertension 40:872-879

34. Lastra G, Habibi J, Whaley-Connell AT et al (2009) Direct renin inhibition improves systemic insulin resistance and skeletal muscle glucose transport in a transgenic rodent model of tissue renin overexpression. Endocrinology 150:2561-2568

35. Chu KY, Cheng Q, Chen C et al (2010) Angiotensin II exerts glucose-dependent effects on $\mathrm{Kv}$ currents in mouse pancreatic beta-cells via angiotensin II type 2 receptors. Am J Physiol Cell Physiol 298:C313-C323

36. Levin A, Bakris GL, Molitch M et al (2007) Prevalence of abnormal serum vitamin D, PTH, calcium, and phosphorus in patients with chronic kidney disease: results of the study to evaluate early kidney disease. Kidney Int 71:31-38

37. Sigmund CD (2002) Regulation of renin expression and blood pressure by vitamin $\mathrm{D}(3)$. J Clin Invest 110:155-156

38. Forman JP, Williams JS, Fisher ND (2010) Plasma 25-hydroxyvitamin $\mathrm{D}$ and regulation of the renin-angiotensin system in humans. Hypertension 55:1283-1288

39. Kitamura T, Nakae J, Kitamura $Y$ et al (2002) The forkhead transcription factor Foxo1 links insulin signaling to $\mathrm{Pdx} 1$ regulation of pancreatic beta cell growth. J Clin Invest 110:1839-1847

40. Boquist L, Hellman B, Lernmark A, Taljedal IB (1974) Influence of the mutation "diabetes" on insulin release and islet morphology in mice of different genetic backgrounds. J Cell Biol 62:77-89

41. Kottgen A, Hwang SJ, Rampersaud E et al (2008) TCF7L2 variants associate with CKD progression and renal function in populationbased cohorts. J Am Soc Nephrol 19:1989-1999

42. da Silva XG, Loder MK, McDonald A et al (2009) TCF7L2 regulates late events in insulin secretion from pancreatic islet beta-cells. Diabetes 58:894-905

43. Pessin JE, Saltiel AR (2000) Signaling pathways in insulin action: molecular targets of insulin resistance. J Clin Invest 106:165-169

44. Hennige AM, Ozcan U, Okada T et al (2005) Alterations in growth and apoptosis of insulin receptor substrate-1-deficient beta-cells. Am J Physiol Endocrinol Metab 289:E337-E346

45. Taniyama Y, Hitomi H, Shah A, Alexander RW, Griendling KK (2005) Mechanisms of reactive oxygen species-dependent downregulation of insulin receptor substrate-1 by angiotensin II. Arterioscler Thromb Vasc Biol 25:1142-1147

46. Hashimoto N, Kido Y, Uchida T et al (2006) Ablation of PDK1 in pancreatic beta cells induces diabetes as a result of loss of beta cell mass. Nat Genet 38:589-593

47. Saad MJ, Hartmann LG, de Carvalho DS, Galoro CA, Brenelli SL, Carvalho CR (1995) Effect of glucagon on insulin receptor substrate1 (IRS-1) phosphorylation and association with phosphatidylinositol 3-kinase (PI 3-kinase). FEBS Lett 370:131-134

48. Thorens B (2011) Of fat, beta cells, and diabetes. Cell Metab $14: 439-440$

49. www.fda.gov/drugs/drugsafety/ucm300889.htm, last accessed, 8 November, 2012

50. Parving HH, Brenner BM, McMurray JJ et al (2012) Cardiorenal end points in a trial of aliskiren for type 2 diabetes. N Engl J Med. doi:10.1056/NEJMoa1208799 